\title{
Harmful impact of air pollution on severe acute exacerbation of chronic obstructive pulmonary disease: particulate matter is hazardous
}

This article was published in the following Dove Press journal: International Journal of COPD

\author{
Juwhan Choi \\ Jee Youn Oh \\ Young Seok Lee \\ Kyung Hoon Min \\ Gyu Young Hur \\ Sung Yong Lee \\ Kyung Ho Kang \\ Jae Jeong Shim
}

Division of Respiratory, Allergy and Critical Care Medicine, Department of Internal Medicine, Korea University Guro Hospital, Korea University College of Medicine, Seoul, Republic of Korea
Correspondence: Jae Jeong Shim Division of Respiratory and Critical Care Medicine, Department of Internal Medicine, Korea University Guro Hospital, Korea University College of Medicine, 148 Gurodong-ro, Guro-gu, Seoul 08308, Republic of Korea

Tel +82226261029

Fax +82 22626 II 66

Email jaejshim@kumc.or.kr
Introduction: Particulate matter and air pollution in Korea are becoming worse. There is a lack of research regarding the impact of particulate matter on patients with COPD. Therefore, the purpose of this study was to investigate the effects of various air pollution factors, including particulate matter, on the incidence rate of severe acute exacerbations of COPD (AECOPD) events.

Methods: We analyzed the relationship between air pollutants and AECOPD events that required hospitalization at Guro Hospital in Korea from January 1, 2015 to May 31, 2017. We used general linear models with Poisson distribution and log-transformation to obtain adjusted relative risk (RR). We conducted further analysis through the Comprehensive Air-quality Index (CAI) that is used in Korea.

Results: Among various other air pollutants, particulate matter was identified as a major source of air pollution in Korea. When the CAI score was over 50, the incidence rate of severe AECOPD events was statistically significantly higher [RR 1.612, 95\% CI, 1.065-2.440, $P=0.024]$. Additionally, the particulate matter levels 3 days before hospitalization were statistically significant [RR 1.003, 95\% CI, 1.001-1.005, $P=0.006$ ].

Conclusion: Particulate matter and air pollution increase the incidence rate of severe AECOPD events. COPD patients should be cautioned against outdoor activities when particulate matter levels are high.

Keywords: air pollution, particulate matter, air quality index, acute exacerbation, COPD

\section{Introduction}

Air pollution is a global environmental issue. ${ }^{1}$ Among the many air pollutants, the problem of particulate matter (PM) in China is causing global concern. ${ }^{2} \mathrm{PM}$ is a complex mixture of extremely small solid and liquid particles (diameter of less than $10 \mu \mathrm{m}$ ) floating in air. Similarly, concerns regarding PM have also grown in Korea over the past several years. ${ }^{3}$ According to some surveys, the capital of Korea, Seoul, is a city with a high concentration of PM. Currently, the Korean government and organizations are preparing various policies and regulations regarding PM.

Many countries and government agencies are using the air quality index (AQI) in assessing the degree of air pollution. ${ }^{4}$ Air is a mixture of various gases, and AQI is obtained by integrating the pollution degree of various gases, like PM, ozone $\left(\mathrm{O}_{3}\right)$, nitrogen dioxide $\left(\mathrm{NO}_{2}\right)$, sulfur dioxide $\left(\mathrm{SO}_{2}\right)$, and carbon monoxide $(\mathrm{CO})$. Korea uses the Comprehensive Air-quality Index (CAI). The CAI is used to analyze and prevent the effects of air pollution on public health. ${ }^{5}$ However, there is an insufficiency of research about clinical adverse effects of PM and air pollution in Korea. 
PM is thought to cause direct damage to the lungs, bronchi and $\operatorname{skin}^{6,7}$ as well as an abnormal inflammatory response and coagulopathy, resulting in various diseases. ${ }^{8,9} \mathrm{PM}$ can have a more harmful impact on patients with pulmonary diseases, such as COPD. ${ }^{10}$ However, studies regarding the harmful effects of PM on COPD and acute exacerbation of COPD (AECOPD) are lacking. There has been recent study in Korea showing that the concentration of PM was associated with hospitalization for asthma, acute bronchitis, and acute rhinitis. ${ }^{11}$ However most studies on PM in Korea have focused on asthma or cardiovascular disease. ${ }^{12,13}$ Therefore, the purpose of this study was to investigate the harmful impact of various air pollution factors, including PM, on the incidence rate of severe AECOPD events.

\section{Materials and methods Collection of patient data}

We found AECOPD events that required hospitalization at Korea University Guro Hospital by searching the hospital's electronic records. This study was approved by the Institutional Review Board of Korea University Guro Hospital (approval number KUGH16131-002). The study is a retrospective analysis, so did not need patient consent. We maintain the confidentiality of patient information. According to inclusion and exclusion criteria, 375 severe AECOPD events were identified. We defined severe AECOPD events as those that required hospitalization. ${ }^{14}$

Patients were included if they: 1) had undergone a pulmonary function test within 1 year that showed an obstructive pattern (a ratio of forced expiratory volume in the first second $\left[\mathrm{FEV}_{1}\right]$ to forced vital capacity [FVC] of less than $70 \%)^{14}$ before the admission event; 2 ) had been hospitalized for "an acute worsening of respiratory symptoms that result in additional therapy, like short-acting inhaled beta2-agonists, maintenance therapy with long-acting bronchodilators, systemic corticosteroids, oxygen therapy, and antibiotics"; 15 3 ) had been hospitalized through an emergency room or an outpatient clinic between January 1, 2015 and May 31, 2017; and 4) were over 40 years old.
Patients were excluded if: 1) they had cancer, an autoimmune disease, or an immune deficiency; or 2) the cause of admission was not AECOPD, but was, for example, acute heart failure, acute pulmonary edema, acute pulmonary embolism, pneumothorax, or arrhythmia.

\section{Collection of air pollution and climate data}

Air pollution and climate data were provided by the government of the Republic of South Korea and the city of Seoul. The air pollution measuring station was located in Guro, where the hospital is located; Guro is an area in Seoul.

We collected data on representative gases related to air pollution: PM with a diameter of less than $10 \mu \mathrm{m}\left(\mathrm{PM}_{10}\right)$, $\mathrm{PM}$ with a diameter of less than $2.5 \mu \mathrm{m}\left(\mathrm{PM}_{2.5}\right)$, ozone $\left(\mathrm{O}_{3}\right)$, nitrogen dioxide $\left(\mathrm{NO}_{2}\right)$, sulfur dioxide $\left(\mathrm{SO}_{2}\right)$, and carbon monoxide $(\mathrm{CO})$. We also received temperature and humidity data. All data included hourly, daily, weekly, and monthly average values.

\section{Comprehensive Air-quality Index in Korea}

We conducted further analysis through the CAI used in Korea. The CAI is a way of describing ambient air quality based on the level of health risks associated with the level of air pollution. The CAI has values of 0 through 500, which are divided into four categories. The higher the CAI value is, the greater the level of air pollution. We calculated the score for each air pollutant and used the highest score as the representative value. If there were two or more cases for which the calculated score was higher than the $\mathrm{C}$ grade, we added 50 points to the highest score. Detailed information regarding the CAI is shown in Tables 1 and 2.

\section{Statistical analysis}

Data were analyzed using SPSS 20 software (SPSS for windows, IBM Corporation, Armonk, NY, USA). Data points are reported as mean $\pm \mathrm{SD}$. The association between the incidence rate of severe AECOPD events and $\mathrm{PM}_{10}$ concentration or CAI score was analyzed by the

Table I Comprehensive Air-quality Index (CAI)

\begin{tabular}{llll}
\hline Category & Description & Values & Health effects \\
\hline A & Good & $0-50$ & A level that will not impact patients suffering from diseases related to air pollution \\
B & Moderate & $5 I-100$ & A level that may have minimal impact on patients in cases of chronic exposure \\
C & Unhealthy & $10 I-250$ & $\begin{array}{l}\text { A level that may have harmful impacts on patients and members of sensitive groups, and that may } \\
\text { also cause the general public unpleasant side effects }\end{array}$ \\
D & Very unhealthy & $25 I-500$ & $\begin{array}{l}\text { A level that may require emergency measures for patients and members of sensitive groups, and } \\
\text { that may have harmful impacts on the general public }\end{array}$ \\
\hline
\end{tabular}


Table 2 The relationship between CAI value and air pollutants

\begin{tabular}{|c|c|c|c|c|}
\hline Category & $\mathbf{A}$ & B & C & D \\
\hline$\overline{\text { Description }}$ & Good & Moderate & $\overline{\text { Unhealthy }}$ & Very unhealthy \\
\hline Values & $0-50$ & $51-100$ & $101-250$ & $25 I-500$ \\
\hline $\mathrm{PM}_{10}\left(\mu \mathrm{g} / \mathrm{m}^{3}\right)$ & $0-30$ & $31-80$ & $8 I-150$ & $|5|-600$ \\
\hline $\mathrm{PM}_{2.5}\left(\mu \mathrm{g} / \mathrm{m}^{3}\right)$ & $0-15$ & $16-50$ & $51-100$ & $101-500$ \\
\hline $\mathrm{O}_{3}(\mathrm{ppm})$ & $0-0.030$ & $0.031-0.090$ & $0.091-0.150$ & $0.150-0.600$ \\
\hline $\mathrm{NO}_{2}(\mathrm{ppm})$ & $0-0.030$ & $0.031-0.060$ & $0.061-0.200$ & $0.20 \mathrm{I}-2$ \\
\hline $\mathrm{SO}_{2}(\mathrm{ppm})$ & $0-0.020$ & $0.021-0.050$ & $0.05 I-0.150$ & $0.151-1$ \\
\hline $\mathrm{CO}$ (ppm) & $0-2$ & $2.01-9$ & $9.01-15$ & $|5.0|-50$ \\
\hline
\end{tabular}

Abbreviations: CAl, Comprehensive Air-quality Index; $\mathrm{PM}_{10}$, particulate matter with a diameter of less than $10 \mu \mathrm{m} ; \mathrm{PM}_{2.5}$, particulate matter with a diameter of less than $2.5 \mu \mathrm{m} ; \mathrm{O}_{3}$, ozone; $\mathrm{NO}_{2}$, nitrogen dioxide; $\mathrm{SO}_{2}$, sulfur dioxide; $\mathrm{CO}$, carbon monoxide.

application of general linear models with a Poisson distribution. General linear models with a Poisson distribution and log-transformation were used to analyze frequency or incidence rate in previous studies; this method is called Poisson regression analysis. ${ }^{11,16,17}$

The atmosphere is a complex system, which is influenced by various air pollutant gases and weather. To evaluate various air pollutant gases, we used the CAI, which combines six main air pollutants. Additionally, we analyzed the temperature and humidity in a Poisson regression analysis to adjust for the effect of weather. And, we also adjusted for day of the week (DOW) and holiday (Saturdays, Sundays, and public holidays) in a Poisson regression. A 95\% CI was calculated using the Poisson regression analysis, and the CI range was defined as statistically significant when it was greater than 1 .

\section{Results}

\section{Air pollution and climate data in Korea}

In Korea, $\mathrm{PM}_{10}$ and $\mathrm{PM}_{2.5}$ were identified as major air pollutants. There was no seasonal variation found for $\mathrm{PM}_{2.5}$. However, seasonal variation was found for $\mathrm{PM}_{10}$. $\mathrm{PM}_{10}$ was high between January and May every year. As a result, the CAI score also tended to increase during these months (Figure 1A). Korea has four distinct seasons; thus, the temperature and humidity showed distinct annual variation. Humidity was low in winter and high in summer and autumn (Figure 1B). The incidence rate of severe AECOPD events was found to be high in winter and spring (Figure 1C). Detailed monthly average data on levels of six air pollutant gases, temperature, and humidity are presented in Table 3.
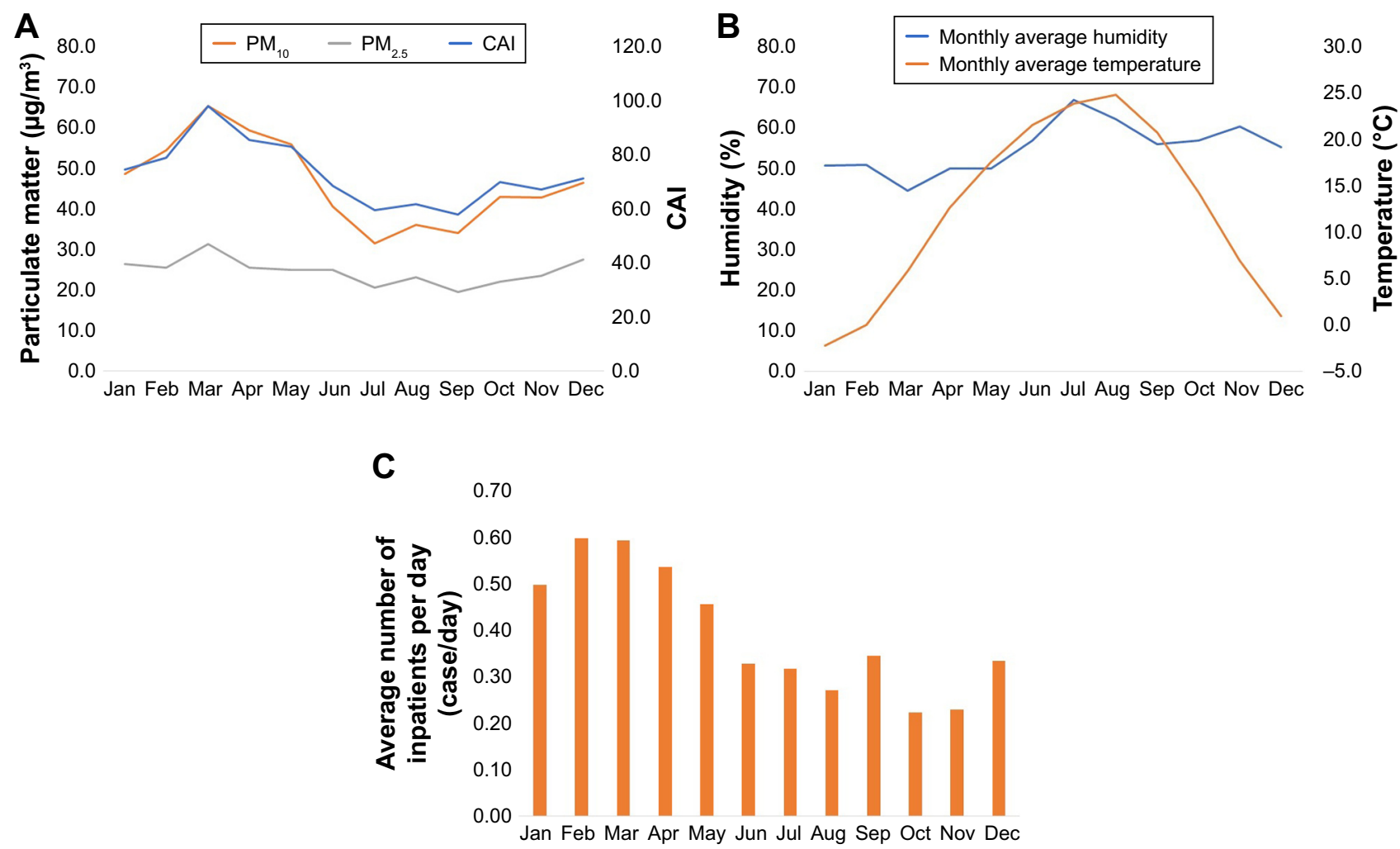

Figure I Monthly average data related to air pollutants and number of inpatients per day. (A) Monthly average $\mathrm{CAI}, \mathrm{PM}_{10}$, and $\mathrm{PM}_{2.5}$. (B) Monthly average humidity and temperature. (C) Monthly average number of inpatients (patients admitted to hospital for AECOPD) per day.

Notes: The average from January to May is from 2015 to 2017; the average from June to December is from 2015 to 2016.

Abbreviations: CAI, Comprehensive Air-quality Index; $\mathrm{PM}_{10}$, particulate matter with a diameter of less than $10 \mu \mathrm{m}$; $\mathrm{PM}_{2.5}$, particulate matter with a diameter of less than $2.5 \mu \mathrm{m}$. 
Table 3 Monthly average data related to air pollutants

\begin{tabular}{|c|c|c|c|c|c|c|c|c|c|}
\hline & CAI & $\begin{array}{l}\mathbf{P M}_{10} \\
\left(\mu \mathrm{g} / \mathrm{m}^{3}\right)\end{array}$ & $\begin{array}{l}\mathbf{P M}_{2.5} \\
\left(\mu \mathrm{g} / \mathrm{m}^{3}\right)\end{array}$ & $\begin{array}{l}\mathrm{O}_{3} \\
\text { (ppm) }\end{array}$ & $\begin{array}{l}\mathrm{NO}_{2} \\
(\mathrm{ppm})\end{array}$ & $\begin{array}{l}\mathrm{SO}_{2} \\
(\mathrm{ppm})\end{array}$ & $\begin{array}{l}\mathrm{CO} \\
\text { (ppm) }\end{array}$ & $\begin{array}{l}\text { Temperature } \\
\left({ }^{\circ} \mathrm{C}\right)\end{array}$ & $\begin{array}{l}\text { Humidity } \\
\text { (\%) }\end{array}$ \\
\hline Jan & $77.1 \pm 29.3$ & $50.2 \pm 18.9$ & $27.4 \pm|| .7$ & $0.012 \pm 0.006$ & $0.03 I \pm 0.01 I$ & $0.006 \pm 0.001$ & $0.7 \pm 0.2$ & $-2.0 \pm 4.2$ & $54.7 \pm 12.4$ \\
\hline Feb & $81.5 \pm 45.0$ & $56.2 \pm 41.6$ & $26.3 \pm 10.7$ & $0.016 \pm 0.006$ & $0.030 \pm 0.010$ & $0.007 \pm 0.002$ & $0.6 \pm 0.2$ & $0.4 \pm 3.6$ & $54.9 \pm 13.5$ \\
\hline Mar & $101.2 \pm 50.2$ & $67.6 \pm 28.2$ & $32.4 \pm 12.4$ & $0.024 \pm 0.007$ & $0.03 I \pm 0.01 I$ & $0.007 \pm 0.002$ & $0.6 \pm 0.2$ & $6.7 \pm 4.0$ & $47.9 \pm 11.9$ \\
\hline Apr & $88.3 \pm 34.8$ & $61.3 \pm 26.4$ & $26.3 \pm 10.0$ & $0.031 \pm 0.010$ & $0.027 \pm 0.008$ & $0.006 \pm 0.002$ & $0.6 \pm 0.1$ & $14.0 \pm 2.8$ & $53.8 \pm 16.5$ \\
\hline May & $85.8 \pm 41.3$ & $57.8 \pm 27.3$ & $25.8 \pm 10.7$ & $0.038 \pm 0.008$ & $0.023 \pm 0.007$ & $0.007 \pm 0.00 \mathrm{I}$ & $0.5 \pm 0.1$ & $19.3 \pm 2.7$ & $53.7 \pm 14.6$ \\
\hline Jun & $70.9 \pm 10.6$ & $42.1 \pm 13.6$ & $25.8 \pm 8.7$ & $0.039 \pm 0.007$ & $0.023 \pm 0.006$ & $0.006 \pm 0.001$ & $0.4 \pm 0.1$ & $22.5 \pm 23.6$ & $61.3 \pm 11.5$ \\
\hline Jul & $66.8 \pm 17.9$ & $32.5 \pm 14.8$ & $21.3 \pm 10.2$ & $0.034 \pm 0.015$ & $0.020 \pm 0.006$ & $0.005 \pm 0.001$ & $0.4 \pm 0.1$ & $23.9 \pm 26.0$ & $72.0 \pm 11.3$ \\
\hline Aug & $62.1 \pm 16.2$ & $37.4 \pm 15.1$ & $24.0 \pm 11.2$ & $0.034 \pm 0.011$ & $0.020 \pm 0.007$ & $0.006 \pm 0.001$ & $0.4 \pm 0.1$ & $28.3 \pm 27.1$ & $66.8 \pm 6.7$ \\
\hline Sep & $63.3 \pm 13.8$ & $35.3 \pm 13.9$ & $20.2 \pm 9.4$ & $0.028 \pm 0.008$ & $0.024 \pm 0.009$ & $0.005 \pm 0.00 \mathrm{I}$ & $0.4 \pm 0.1$ & $24.6 \pm 22.7$ & $60.4 \pm 10.8$ \\
\hline Oct & $58.1 \pm 37.9$ & $44.4 \pm 23.4$ & $22.8 \pm 15.1$ & $0.019 \pm 0.006$ & $0.028 \pm 0.01 \mathrm{I}$ & $0.006 \pm 0.001$ & $0.5 \pm 0.2$ & $\mid 8.7 \pm 15.8$ & $61.3 \pm 11.4$ \\
\hline Nov & $79.1 \pm 26.0$ & $44.2 \pm 20.1$ & $24.3 \pm 12.4$ & $0.012 \pm 0.007$ & $0.029 \pm 0.009$ & $0.006 \pm 0.001$ & $0.6 \pm 0.2$ & $4.3 \pm 7.8$ & $65.0 \pm 12.6$ \\
\hline Dec & $70.0 \pm 27.8$ & $48.0 \pm 16.5$ & $28.5 \pm 11.8$ & $0.009 \pm 0.006$ & $0.032 \pm 0.009$ & $0.006 \pm 0.001$ & $0.7 \pm 0.2$ & $4.1 \pm 1.4$ & $59.5 \pm 12.4$ \\
\hline
\end{tabular}

Notes: The average from January to May is from 2015 to 20I7; the average from June to December is from 2015 to 2016 . Numbers are presented as mean \pm SD.

Abbreviations: CAl, Comprehensive Air-quality Index; $\mathrm{PM}_{10}$, particulate matter with a diameter of less than $10 \mu \mathrm{m}$; $\mathrm{PM}_{2.5}$, particulate matter with a diameter of less than $2.5 \mu \mathrm{m} ; \mathrm{O}_{3}$, ozone; $\mathrm{NO}_{2}$, nitrogen dioxide; $\mathrm{SO}_{2}$, sulfur dioxide; $\mathrm{CO}$, carbon monoxide.

\section{Comprehensive Air-quality Index}

When classified as CAI categories, 0.26 cases were hospitalized per day in category $\mathrm{A}$, and 0.45 cases were hospitalized per day in category B. However, there was no significant difference between categories B and C (Table 4). In addition, we analyzed the adjusted relative risk (RR) using the CAI 50, which is the distinguishing value between Categories $\mathrm{A}$ and $\mathrm{B}$, and 100, which is the distinguishing value between Categories B and C. When analyzed on the cutoff value of 50, the incidence rate of severe AECOPD events was statistically significantly higher in the group with CAI values higher than 50 (RR 1.612, 95\% CI 1.065-2.440, $P=0.024$ ). However, when analyzed on the cutoff value of 100 , there was no statistically significant difference between the two groups (Table 5).

\section{Relationship between exposure time of air pollutant and hospitalization}

We assessed the time at which PM and air pollution have the greatest effect on AECOPD events. $\mathrm{PM}_{10}$ levels 3 days before hospitalization were statistically significant (RR 1.003, 95\% CI 1.001-1.005, $P=0.006$ ) (Figure 2A). Similarly, the CAI value 3 days before hospitalization was statistically significant (RR 1.002, 95\% CI 1.000-1.004, $P=0.019$ ) (Figure 2B). In addition, the adjusted relative risk increased by 1.05 for every $10 \mu \mathrm{g} / \mathrm{m}^{3}$ of increased $\mathrm{PM}_{10}$ average level from the day of hospitalization to 3 days before hospitalization $(P=0.020)$.

\section{Discussion}

Our study is the first study in Korea to investigate how PM and air pollution affect the incidence rate of severe AECOPD events. We analyzed six gases $\left(\mathrm{PM}_{10}, \mathrm{PM}_{2.5}, \mathrm{CO}, \mathrm{O}_{3}, \mathrm{NO}_{2}\right.$, and $\mathrm{SO}_{2}$ ) that are considered to be representative air pollutants. ${ }^{18}$ Additionally, we used an AQI called the CAI, which is used in Korea. ${ }^{19}$ Because air pollutant concentration and clearance rate vary depending on weather, we analyzed temperature and humidity together, using Poisson regression analysis. ${ }^{20}$ In addition, we adjusted for DOW and holidays in a Poisson regression analysis. In Korea, the main reason for choosing a particular hospital is the distance to the hospital from the patient's house; therefore, the spatial location is based on the Guro area, where the hospital is located. Daily, weekly, and monthly analyses were performed. According to our results, $\mathrm{PM}$ and air pollution increase the incidence rate of severe AECOPD events in Korea.

Table 4 The association between CAI and severe AECOPD events

\begin{tabular}{|c|c|c|c|c|c|}
\hline CAl category & $\mathbf{A}$ & B & C & $\mathbf{D}$ & Total \\
\hline CAl description & $\overline{\text { Good }}$ & $\overline{\text { Moderate }}$ & $\overline{\text { Unhealthy }}$ & $\overline{\text { Very unhealthy }}$ & \\
\hline Total number of days & 94 & 696 & 82 & 10 & 882 \\
\hline Total number of inpatients (cases) & 24 & 311 & 33 & 6 & 374 \\
\hline Average number of inpatients per day (cases/day) & 0.26 & 0.45 & 0.40 & 0.60 & \\
\hline
\end{tabular}

Abbreviations: CAI, Comprehensive Air-quality Index; AECOPD, acute exacerbations of chronic obstructive pulmonary disease. 
Table 5 Risk of severe AECOPD events with cutoff values of CAI 50 and 100

\begin{tabular}{lllll}
\hline Cutoff value & Factors & RR & $\mathbf{9 5 \%} \mathbf{C l}$ & P-value \\
\hline CAI 50 & $\mathrm{CAl} \leq 50$ & $\mathrm{I}$ & & \\
& $\mathrm{CAl}>50$ & $\mathrm{I} .612$ & $1.065-2.440$ & 0.024 \\
& Temperature $\left({ }^{\circ} \mathrm{C}\right)$ & 0.989 & $0.979-0.999$ & 0.034 \\
& Humidity $(\%)$ & 0.994 & $0.986-1.00 \mathrm{I}$ & 0.110 \\
$\mathrm{CAI} 100$ & $\mathrm{CAl} \leq 100$ & $\mathrm{I}$ & & \\
& $\mathrm{CAl}>100$ & $\mathrm{I} .025$ & $0.736-\mathrm{I} .429$ & 0.882 \\
& Temperature $\left({ }^{\circ} \mathrm{C}\right)$ & 0.989 & $0.979-0.999$ & 0.033 \\
& Humidity $(\%)$ & 0.993 & $0.986-1.00 \mathrm{I}$ & 0.074 \\
\hline
\end{tabular}

Abbreviations: AECOPD, acute exacerbations of chronic obstructive pulmonary disease; CAI, Comprehensive Air-quality Index; RR, adjusted relative risk.

Air pollution is a major global problem affecting health. ${ }^{21}$ $\mathrm{PM}$ is the most serious source of air pollution in Korea. ${ }^{11}$ Our study did not find high concentrations of other air pollutants $\left(\mathrm{CO}, \mathrm{O}_{3}, \mathrm{NO}_{2}\right.$, and $\left.\mathrm{SO}_{2}\right)$. For many years, large amounts of PM from China have been flowing into Korea. ${ }^{22,23}$ $\mathrm{PM}$ is generated in various ways in Korea, such as through the construction industry, automobile use, and heating systems. ${ }^{24,25}$ The number of PM warnings has also steadily increased in Korea since 2013. According to our results, $\mathrm{PM}_{10}$ and $\mathrm{PM}_{2.5}$ levels have not decreased for several years. Also, $\mathrm{PM}_{10}$ appears to increase during winter and spring each year. In Korea, COPD patients should pay attention to daily activities in winter and spring when there are high levels of PM. For example COPD patients should avoid outdoor activities, use masks, and keep windows closed at home when PM levels are high.

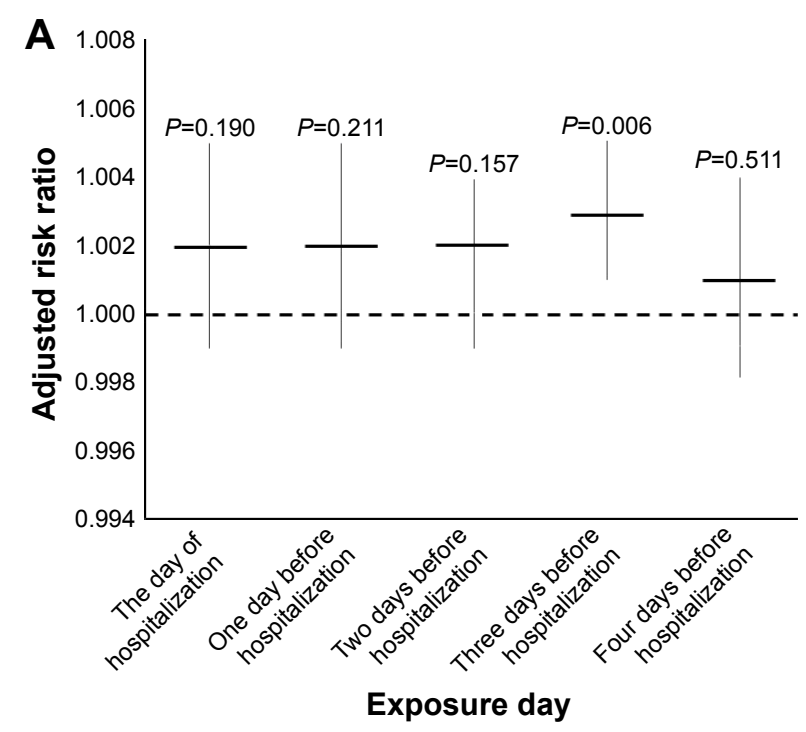

PM acts as an irritant at the moment of respiration, and damages the lungs, bronchi, and mucous membranes. ${ }^{26}$ In addition to acute damage, PM enters the body and causes abnormal inflammatory responses and coagulopathy. ${ }^{9}$ Recent study shows that $\mathrm{PM}_{2.5}$ contributes to abnormal airway inflammation through various signaling pathways, such as epidermal growth factor receptor (EGFR), mitogenactivated protein kinase (MAPK), nuclear factor (NF)-kB and the interleukin pathway. ${ }^{27-29}$ Also, $\mathrm{PM}_{2.5}$ affects the fractional concentration of exhaled nitric oxide (FeNO), which can lead to airway inflammation in COPD patients. ${ }^{30}$ These abnormal inflammatory responses and signaling pathways are related to a variety of diseases, such as myocardial infarction, stroke, embolism, and cancer. ${ }^{31-33}$ Furthermore, when PM is absorbed into the body it can produce oxidative stress. ${ }^{34} \mathrm{PM}$ directly increases reactive oxygen species, which cause DNA damage. ${ }^{35}$ Transition metals or organic compounds may modulate mitochondria or nicotinamide adenine dinucleotide phosphate (NADPH)-oxidase, which deteriorates their function..$^{36}$ Our results showed that $\mathrm{PM}_{10}$ and CAI levels at 3 days before hospitalization had the greatest correlation with admission rate for severe AECOPD events. We estimate that this is due to abnormal inflammatory response and oxidative stress. Because of these responses, it is necessary to consider not only acute periods, but also sub-acute and chronic periods, in the study of PM.

Various epidemiological studies related to PM have been conducted, mainly in China. Several systematic reviews and

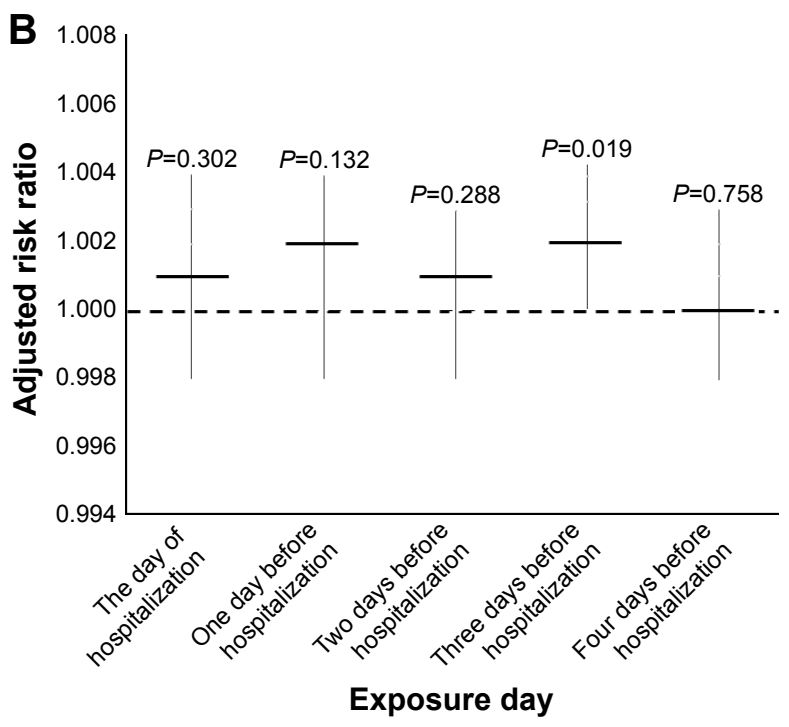

Figure 2 Association of $\mathrm{PM}_{10}, \mathrm{CAl}$ and severe AECOPD events after adjustment for humidity and temperature. (A) The association of PM 10 and severe $\mathrm{AECOPD}$ events. (B) The association of CAI and severe AECOPD events.

Abbreviations: $\mathrm{PM}_{10}$, particulate matter with a diameter of less than $10 \mu \mathrm{m}$; CAl, Comprehensive Air-quality Index; AECOPD, acute exacerbations of chronic obstructive pulmonary disease. 
meta-analyses have shown that PM exposure is associated with mortality, hospitalization and emergency department visits in COPD patients. ${ }^{37-39}$ These results were confirmed with both $\mathrm{PM}_{10}$ and $\mathrm{PM}_{2.5}$. PM may be related to various respiratory diseases, such as lung cancer, COPD, asthma, bronchiectasis and chronic cough. ${ }^{40,41}$ There is also a relationship with the prognosis and mortality of the general public. ${ }^{42,43}$ It is possible that not only AECOPD, but also acute exacerbation of asthma and bronchiectasis, may increase. ${ }^{44}$ If air pollution becomes worse, it may become a major cause of COPD, along with smoking. ${ }^{45}$ Long-term studies related to the occurrence of COPD are needed to better understand the disease.

Most guidelines and government policies about PM and air pollution are based on the general public, not COPD patients. ${ }^{46,47}$ However, patients with pulmonary disease can be seriously affected by lower levels of PM which may not affect healthy people. Our study also showed a significant difference in incidence rate in CAI 50, not in CAI 100, which is the standard for the general public in Korea. Specific guidelines and government support for COPD patients are needed.

Our study has some limitations. First, this study is a single center study. Guro is one of the regions in Korea where the PM level is high. Analysis in areas with low PM levels is required. Secondly, only hospitalized events were analyzed. It is unclear whether the incidence rate of AECOPD events that do not require hospitalization will increase as well. A study encompassing both types of AECOPD events is needed. Third, the causes of AECOPD were not analyzed. The causes of AECOPD can be classified as either infectious or non-infectious. Infectious causes include bacteria or viruses; non-infectious causes include air pollution, drugs, cold temperatures, allergens, smoking and emotional stress. Further analysis of laboratory findings after admission or history taking will help determine the cause of AECOPD. However, this study is a retrospective study; some of the patients' in-hospital data were insufficient and we could not analyze the causes of AECOPD. Fourth, as representative data of air pollution, we used ambient pollutant concentrations from a monitoring station in Guro. This may be different to individual PM exposure, and this might lead to underestimation or overestimation of the RR.

However, we adjusted various factors that could affect air pollution through Poisson regression analysis, such as the temperature, humidity, DOW and holiday; and we conducted analysis including six representative air pollution gases and the AQI. In addition, we performed a time analysis of the most influential exposure periods. In the future, large-scale studies will be needed on air pollution and AECOPD in various regions.

\section{Conclusion}

$\mathrm{PM}$ and air pollution increase the incidence rate of severe AECOPD events. PM and air pollution are considered to be major non-infectious causes of AECOPD events. COPD patients should be cautioned against outdoor activities when PM levels are high.

\section{Author contributions}

All authors contributed toward data analysis, drafting and revising the paper and agree to be accountable for all aspects of the work.

\section{Disclosure}

The authors report no conflicts of interest in this work.

\section{References}

1. Colao A, Muscogiuri G, Piscitelli P. Environment and health: not only cancer. Int J Environ Res Public Health. 2016;13(7):724.

2. Wang J, Zhao B, Wang S, et al. Particulate matter pollution over China and the effects of control policies. Sci Total Environ. 2017;584-585: 426-447.

3. Kamimura A, ArmentaB, Nourian M, AssasnikN, NourianK, Chernenko A. Perceived environmental pollution and its impact on health in China, Japan, and South Korea. J Prev Med Public Health. 2017;50(3): 188-194.

4. Thach TQ, Tsang H, Cao P, Ho LM. A novel method to construct an air quality index based on air pollution profiles. Int J Hyg Environ Health. 2018;221(1):17-26.

5. Choi G, Heo S, Lee JT. Assessment of environmental injustice in Korea using synthetic air quality index and multiple indicators of socioeconomic status: A cross-sectional study. J Air Waste Manag Assoc. 2016;66(1): $28-37$.

6. Wang C, Cai J, Chen R, et al. Personal exposure to fine particulate matter, lung function and serum club cell secretory protein (Clara). Environ Pollut. 2017;225:450-455.

7. Kim KE, Cho D, Park HJ. Air pollution and skin diseases: Adverse effects of airborne particulate matter on various skin diseases. Life Sci. 2016;152:126-134.

8. Bind MA, Baccarelli A, Zanobetti A, et al. Air pollution and markers of coagulation, inflammation, and endothelial function: associations and epigene-environment interactions in an elderly cohort. Epidemiology. 2012;23(2):332-340.

9. Liu C, Cai J, Qiao L, et al. The acute effects of fine particulate matter constituents on blood inflammation and coagulation. Environ Sci Technol. 2017;51(14):8128-8137.

10. Ni L, Chuang CC, Zuo L. Fine particulate matter in acute exacerbation of COPD. Front Physiol. 2015;6:294.

11. Jo EJ, Lee WS, Jo HY, et al. Effects of particulate matter on respiratory disease and the impact of meteorological factors in Busan, Korea. Respir Med. 2017;124:79-87.

12. Park JW, Lim YH, Kyung SY, et al. Effects of ambient particulate matter on peak expiratory flow rates and respiratory symptoms of asthmatics during Asian dust periods in Korea. Respirology. 2005; 10(4):470-476. 
13. Hwang SH, Lee JY, Yi SM, Kim H. Associations of particulate matter and its components with emergency room visits for cardiovascular and respiratory diseases. PLoS One. 2017;12(8):e0183224.

14. Vogelmeier CF, Criner GJ, Martinez FJ, et al. Global Strategy for the Diagnosis, Management, and Prevention of Chronic Obstructive Lung Disease 2017 Report: GOLD Executive Summary. Eur Respir J. 2017;49(3):1700214.

15. Wedzicha JA, Seemungal TA. COPD exacerbations: defining their cause and prevention. Lancet. 2007;370(9589):786-796.

16. Nastos PT, Matzarakis A. Weather impacts on respiratory infections in Athens, Greece. Int J Biometeorol. 2006;50(6):358-369.

17. Panagiotakos DB, Chrysohoou C, Pitsavos C, et al. Climatological variations in daily hospital admissions for acute coronary syndromes. Int J Cardiol. 2004;94(2-3):229-233.

18. Kang SH, Heo J, Oh IY, et al. Ambient air pollution and out-of-hospital cardiac arrest. Int J Cardiol. 2016;203:1086-1092.

19. Oh T, Kim M, Lim J, et al. A real-time monitoring and assessment method for calculation of total amounts of indoor air pollutants emitted in subway stations. J Air Waste Manag Assoc. 2012;62(5):517-526.

20. D'Amato G, Pawankar R, Vitale C, et al. Climate change and air pollution: effects on respiratory allergy. Allergy Asthma Immunol Res. 2016; 8(5):391-395.

21. Brook RD, Newby DE, Rajagopalan S. The global threat of outdoor ambient air pollution to cardiovascular health: time for intervention. JAMA Cardiol. 2017;2(4):353-354.

22. Wang Y, Ying Q, Hu J, Zhang H. Spatial and temporal variations of six criteria air pollutants in 31 provincial capital cities in China during 2013-2014. Environ Int. 2014;73:413-422.

23. Song C, Wu L, Xie Y, et al. Air pollution in China: Status and spatiotemporal variations. Environ Pollut. 2017;227:334-347.

24. Ogundele LT, Owoade OK, Hopke PK, Olise FS. Heavy metals in industrially emitted particulate matter in Ile-Ife, Nigeria. Environ Res. 2017;156:320-325.

25. Zhang X, Staimer N, Tjoa T, et al. Associations between microvascular function and short-term exposure to traffic-related air pollution and particulate matter oxidative potential. Environ Health. 2016;15(1):81.

26. Del Donno M, Verduri A, Olivieri D. Air pollution and reversible chronic respiratory diseases. Monaldi Arch Chest Dis. 2002;57(3-4): 164-166.

27. Jeong SC, Cho Y, Song MK, Lee E, Ryu JC. Epidermal growth factor receptor (EGFR)-MAPK-nuclear factor(NF)-kappaB-IL8: A possible mechanism of particulate matter(PM) 2.5-induced lung toxicity. Environ Toxicol. 2017;32(5):1628-1636.

28. Kim HJ, Choi MG, Park MK, Seo YR. Predictive and prognostic biomarkers of respiratory diseases due to particulate matter exposure. J Cancer Prev. 2017;22(1):6-15.

29. Yan Z, Jin Y, An Z, Liu Y, Samet JM, Wu W. Inflammatory cell signaling following exposures to particulate matter and ozone. Biochim Biophys Acta. 2016;1860(12):2826-2834.

30. Chen R, Qiao L, Li H, et al. Fine particulate matter constituents, nitric oxide synthase dna methylation and exhaled nitric oxide. Environ Sci Technol. 2015;49(19):11859-11865.

31. McGuinn LA, Ward-Caviness C, Neas LM, et al. Fine particulate matter and cardiovascular disease: Comparison of assessment methods for long-term exposure. Environ Res. 2017;159:16-23.
32. Tian $\mathrm{Y}, \mathrm{Xiang} \mathrm{X}, \mathrm{Wu} \mathrm{Y}$, et al. Fine particulate air pollution and first hospital admissions for ischemic stroke in Beijing, China. Sci Rep. 2017; 7(1):3897.

33. Hoek G, Brunekreef B, Fischer P, van Wijnen J. The association between air pollution and heart failure, arrhythmia, embolism, thrombosis, and other cardiovascular causes of death in a time series study. Epidemiology. 2001;12(3):355-357.

34. Risom L, Moller P, Loft S. Oxidative stress-induced DNA damage by particulate air pollution. Mutat Res. 2005;592(1-2):119-137.

35. Bates JT, Weber RJ, Abrams J, et al. Reactive oxygen species generation linked to sources of atmospheric particulate matter and cardiorespiratory effects. Environ Sci Technol. 2015;49(22):13605-13612.

36. Holland NA, Fraiser CR, Sloan RC 3rd, Devlin RB, Brown DA, Wingard CJ. Ultrafine particulate matter increases cardiac ischemia/ reperfusion injury via mitochondrial permeability transition pore. Cardiovasc Toxicol. 2017;17(4):441-450.

37. Atkinson RW, Kang S, Anderson HR, Mills IC, Walton HA. Epidemiological time series studies of PM2.5 and daily mortality and hospital admissions: a systematic review and meta-analysis. Thorax. 2014;69(7):660-665.

38. DeVries R, Kriebel D, Sama S. Outdoor air pollution and COPD-related emergency department visits, hospital admissions, and mortality: a meta-analysis. COPD. 2017;14(1):113-121.

39. Zhu R, Chen Y, Wu S, Deng F, Liu Y, Yao W. The relationship between particulate matter (PM10) and hospitalizations and mortality of chronic obstructive pulmonary disease: a meta-analysis. COPD. 2013;10(3): 307-315.

40. Gharibvand L, Lawrence Beeson W, Shavlik D, et al. The association between ambient fine particulate matter and incident adenocarcinoma subtype of lung cancer. Environ Health. 2017;16(1):71.

41. Bloemsma LD, Hoek G, Smit LA. Panel studies of air pollution in patients with COPD: Systematic review and meta-analysis. Environ Res. 2016;151:458-468.

42. Shang Y, Sun Z, Cao J, et al. Systematic review of Chinese studies of short-term exposure to air pollution and daily mortality. Environ Int. 2013;54:100-111.

43. Sifaki-Pistolla D, Lionis C, Koinis F, Georgoulias V, Tzanakis N. Cancer Registry of C. Lung cancer and annual mean exposure to outdoor air pollution in Crete, Greece. Eur J Cancer Prev. 2017;26: S208-S214.

44. Pothirat C, Tosukhowong A, Chaiwong W, Liwsrisakun C, Inchai J. Effects of seasonal smog on asthma and COPD exacerbations requiring emergency visits in Chiang Mai, Thailand. Asian Pac J Allergy Immunol. 2016;34(4):284-289.

45. Huls A, Schikowski T. Ambient particulate matter and COPD in China: a challenge for respiratory health research. Thorax. 2017;72(9): $771-772$.

46. Wong CM, Vichit-Vadakan N, Vajanapoom N, et al. Part 5. Public health and air pollution in Asia (PAPA): a combined analysis of four studies of air pollution and mortality. Res Rep Health Eff Inst. 2010;(154): $377-418$.

47. Kutlar Joss M, Eeftens M, Gintowt E, Kappeler R, Kunzli N. Time to harmonize national ambient air quality standards. Int J Public Health. 2017;62(4):453-462.
International Journal of COPD

\section{Publish your work in this journal}

The International Journal of COPD is an international, peer-reviewed journal of therapeutics and pharmacology focusing on concise rapid reporting of clinical studies and reviews in COPD. Special focus is given to the pathophysiological processes underlying the disease, intervention programs, patient focused education, and self management protocols.

\section{Dovepress}

This journal is indexed on PubMed Central, MedLine and CAS. The manuscript management system is completely online and includes a very quick and fair peer-review system, which is all easy to use. Visi http://www.dovepress.com/testimonials.php to read real quotes from published authors. 